Social support, social undermining and coping

in underemployed and unemployed persons

Authors: Peter A Creed, Griffith University - Gold Coast

Kelli Moore, Griffith University - Gold Coast

Contact: Assoc Professor Peter A Creed
School of Applied Psychology
Griffith University - Gold Coast
PMB 50 GCMC
Gold Coast, Queensland Australia 9726

Telephone: $\quad+61755528810$

Facsimile: $\quad+61755528291$

Email: $\quad$ p.creed@griffith.edu.au 


\title{
Social support, social undermining and coping in underemployed and unemployed persons
}

\begin{abstract}
A sample of 171 participants (94 unemployed and 77 underemployed) was administered scales tapping social support, social undermining, coping and psychological distress. It was hypothesised (a) that the unemployed would exhibit less social support, but more social undermining and psychological distress than the underemployed group; (b) that females would report more social support but less social undermining than males; and (c) that social support would be a better predictor of coping than social undermining, but that social undermining would be a better predictor of psychological distress than social support. It was found that the unemployed reported less social support, more psychological distress and less problem-focused coping than the underemployed. Males reported less social support but more emotion-focused coping than females. Social support was a significant individual predictor for both psychological distress and rational/cognitive coping, but not of self-care coping. No group or gender differences were identified for social undermining, and social undermining was not a significant predictor of psychological distress or coping. The role of social undermining in wellbeing in unemployed people is discussed. Practical suggestions are outlined.
\end{abstract}

Keywords: social undermining, social support, coping, unemployed, underemployed 
It has been widely demonstrated that the experience of unemployment impacts negatively on the well-being of those affected (for recent reviews see Murphy \& Athanasou, 1999; Winefield, 1995). For example, when unemployed people are compared with those in employment, the unemployed fare poorer on levels of psychological distress (Henwood \& Miles, 1987) and depression (Feather \& O’Brien, 1986), and present with lower levels of confidence (Wanberg, Watt \& Rumsey, 1996). Most studies in this area have tended to assume the unemployed constitute an homogenous group, and have not examined different subgroups of people who were not in full-time employment (Creed \& Machin, 2002). To be classified as unemployed in Australia, a person would have to have had no paid work in the reference week, been actively looking for work in the previous four weeks, and be available to start work straight away; while being employed meant the person had to have had at least one hour of paid work in the reference week (ABS, 2002). Thus, being unemployed can entail having no paid work at all, or having some paid work (e.g., part-time, casual, intermittent) but wanting more, which can be better classified as underemployed, individuals who work fewer hours than they want to (ABS, 2004). The present study will test for differences across two groups of unemployed participants, those with no paid work at all, and those with some paid work but wanting more, which we have classified as unemployed and underemployed. The variables examined are psychological distress, social support, social undermining and coping.

Social support has been implicated as a moderating variable in relation to well-being, generally (e.g., Abbey, Abramis, \& Caplan, 1985; Ruehlman \& Wolchik, 1988), and specifically in relation to unemployed people (e.g., Feather \& O'Brien, 1987; Jackson, 1999). Social support can be defined in terms of interactions with others that give the recipient emotional support, self-affirmation, instrumental support and information (House, 1981; Vaux, 1988). Theoretically, social support is one of the five latent benefits of employment proposed by Jahoda's (1981) latent deprivation model to account for well- 
being in occupational settings. The other latent benefits are time structure, status, collective goals and meaningful activity. In this model, decline in well-being for unemployed people is associated with the loss of access to the latent benefits of employment. Consistent with the latent deprivation model, Weiss (1973) also theorised that the loss of social support provided by employment would lead to loneliness, boredom, aimlessness and a decline in well-being.

Research evidence has supported the contention that the loss of latent benefits provided by work, especially social support, is associated with a decline in psychological well-being. A number of studies have found satisfaction with personal relationships to be the strongest predictor of well-being in unemployed people (e.g., Broomhall \& Winefield, 1990; Rodriguez, Allen, Frongillo, \& Chandra, 1999). Unemployed samples have been found to report less social support than employed or college student samples (Jackson, 1999), with low social support to be associated with poorer well-being (Jackson, 1999; Warr, Jackson, \& Banks, 1988). Gender differences have been identified, with women more likely to seek social support as a coping strategy (Frydenberg \& Lewis, 1991), and low social support to be more strongly associated with poor well-being in females rather than males (Hammarström \& Janlert (1997). Lastly, in relation to job seeking behaviours, social support has been found to be associated with greater expectations of finding a job (Feather \& O’Brien, 1987).

Although unemployment often results in the reduction in the number and range of social contacts, and reduces the opportunity for making contacts with others, not all studies have found a clear relationship between social support and well-being in unemployed people (e.g., Creed \& Macintyre, 2001; Ensminger \& Celentano, 1988; Warr \& Jackson, 1987). One possible explanation for these inconsistent findings may be the confounding variable of social undermining received by the unemployed. Social undermining includes behaviours directed at the recipient that contain negative affect 
(e.g., disgust or dislike), negative evaluations (e.g., of their actions, behaviours, personal qualities), and behaviours that hinder the attainment of the unemployed person's instrumental goals (Abbey et al., 1985). Unemployed people, who may rely more heavily on family members, may find that their social support is accompanied by a social undermining driven by anger at the unemployed person's job loss or inability to be reemployed (Latack, Kinicki, \& Prussia, 1995).

Social undermining has been shown to be an independent construct from social support, with the two variables not just the two ends of the same continuum, and social undermining not merely being the absence of social support (Vinokur \& van Ryn, 1993). Consistent with the view that the two constructs are independent, social undermining and social support have been found to have different correlates, with social support more likely to be associated with well-being and social undermining more likely to be associated with psychological ill-health (Ruehlman \& Wolchik, 1988). For example, Abbey et al. (1985) found that social undermining, and not social support, was associated with anxiety, depression and quality of life in a sample of students when asked about their close personal relationships. While social support and social undermining appear to be separate constructs it is likely that an interactive effect exists between the two variables (Vinokur, Price \& Caplan, 1996), meaning, for example, that individuals with low social support and high social undermining might be the most disadvantaged.

People often turn to others for material and emotional support to help them cope in times of distress or hardship (Hamilton, Hoffman, Broman, \& Rauma, 1993). Coping has been described as "constantly changing cognitive and behavioural efforts to manage specific external and/or internal demands that are appraised as taxing or exceeding the resources of a person" (Lazarus \& Folkman, 1984, p. 14). Social support (e.g., from friends, family and colleagues) can represent a repertoire of resources that a person can utilise in a stressful situation (Latack et al., 1995), and has been shown to have a 
buffering effect in stressful situations, increasing coping ability and modifying the severity of psychological responses to a stressful situation (e.g., Caplan, Vinokur, Price \& van Ryn, 1989; Cohen \& Wills, 1985). Whereas social support aids the coping process (Latack et al., 1995; Thoits, 1986), social undermining is seen as a direct threat to effective coping (Abbey et al., 1985).

Based on the literature reviewed, it has been identified that the relationship between social support, social undermining and psychological distress has not been examined in the context of different occupational groupings. The current paper aims to examine the differences in social support and social undermining in two samples of respondents who are loosely connected to the labour market, that is, an unemployed and an underemployed group. The paper will also test for the association between these two forms of social relationships and psychological distress in these groups. The current literature supported a relationship between social support and adaptive coping. However, there has been no test of the association between social undermining and coping. The second aim of this paper is to examine the association between social support (operationalised as a coping mechanism) and social undermining (defined as a threat) with coping and psychological distress. It is hypothesised: (a) that the unemployed group will exhibit lower levels of social support, but higher levels of social undermining and psychological distress than the underemployed group; (b) females in the samples will report higher levels of social support and lower levels of social undermining than males; and (c) social support will be a better predictor of coping than social undermining, but that social undermining will be a better predictor of psychological distress than social support. 


\section{Method}

\section{Participants}

A total of 175 surveys were administered, four of which were excluded from the analyses as participants failed to complete all scales adequately, or because of multivariate outliers following data screening. Remaining participants were 171 unemployed young people who, at the time of the survey, were utilising the national employment registry office in south-eastern Queensland, Australia. All participants were in receipt of government sponsored employment welfare. The sample consisted of 86 females $(50.3 \%)$ and 85 males $(49.7 \%)$, whose ages ranged from 16-29 years $(M=20.84$; $S D=3.10)$. Ninety-four participants $(55 \%)$ indicated that they were completely without paid work, and 77 (45\%) indicated that they were underemployed, that is, they had some paid employment but were seeking more.

\section{Measures}

Social Support and Social Undermining. Two scales, developed by Abbey, Abramis and Caplan (1985), were used to measure participants' perceptions of social support (SS) and social undermining (SU) that is received from significant others. A sample item from the 6-item Social Support scale was, "In the last seven days, how much has someone acted in a way that shows you they appreciate what you do?". A sample item from the 5item Social Undermining scale was, "In the last seven days, how much has someone acted in an unpleasant or angry manner towards you?". Participants responded to both scales using a 5-item response format with anchors of not at all/rarely/occasionally/often/a great deal. Higher scores indicate more social support and more social undermining, respectively. Sound psychometric data have been provided on the scales by Vinokur, Schul and Caplan (1987), and Vinokur and Vinokur-Kaplan (1990). 
Psychological Distress. The 12-item version of the General Health Questionnaire (GHQ; Goldberg, 1972) was utilised as a global measure of psychological distress. This version has been widely used and recommended for use as a screening device in occupational settings (e.g., Warr, 1987). Respondents were asked to report on how they felt recently on a range of variables, including cognitive processing, self-esteem, anxiety and depression. Sample items were, "Have you recently been able to concentrate on whatever you're doing?" and "Have you recently felt capable of making decisions about things?". Responses were scored on a four-point scale ranging from zero to three using anchors such as better than usual/same as usual/less than usual/much more than usual. Higher scores indicated greater psychological distress. Goldberg and Williams (1988) reported a mean internal consistency of .85 .

Coping. The Personal Resources Questionnaire (PRQ), which forms one of three domains assessed by the Occupational Stress Inventory (Osipow \& Spokane, 1987), was used to measure coping resources. The PRQ consists of four 10-item sub-scales of: (a) Recreation, which measures recreational use and the benefits derived from this (e.g., "I spend a lot of free time on hobbies"); (b) Self-Care, which measures the level of personal activities aimed at reducing stress (e.g., "I avoid excessive use of alcohol"); (c) Social Support, which measures perceived support from others (e.g., "I have help with the important things that have to be done"); and (d) Rational/Cognitive Coping, which measures cognitive coping skills used to deal with stress (e.g., "When faced with a problem I use a systematic approach"). Minor changes were made to the wording to make the scale suitable for an unemployed sample. Participants were asked to indicate how true each statement was for them on a 5-point scale, using anchors of rarely or never true/occasionally true/often true/usually true/true most of the time. Higher scores indicate more coping. Osipow and Spokane reported satisfactory reliability and validity data. 


\section{Procedure}

The study was a cross-sectional design. Participants who were utilising the national employment office were approached to complete a survey, which contained the preceding scales and questions related to age, gender and employment status.

\section{Results}

Validity of the study measures

To test the construct validity of the scales used in the study, all 63 items (OSI $=40$ items; $\mathrm{SS}=6 ; \mathrm{SU}=5 ; \mathrm{GHQ}=12$ ) were included in a principal axis factor analysis, using a direct oblimin rotation. The Kaiser-Meyer-Olkin Measure of Sampling Adequacy (.78) and Bartlett's Test of Sphericity $\left(\chi^{2}=6037.48, p<.001\right)$ indicated the suitability of the data for factor analysis (Tabachnik \& Fidell, 1996). Initially, seven factors were rotated (to reflect the four subscales of the OSI, and the unitary subscales of the SS, SU and GHQ). However, this solution was factorially complex and not interpretable because of multiple factor loadings for items from the OSI. When these items were removed, five interpretable factors remained. These all had eigenvalues greater than one, and accounted for $53.53 \%$ of the variance. Examination of the pattern matrix indicated that items from the SS, SU and GHQ loaded onto their respective factors, and that two factors accounted for the OSI. OSI Factor 1 (Qs 38, 34, 37, 40, 39, 35, 32, 14, 36, 33, 22, 12 and 11) consisted of items mainly from the rational/cognitive subscale and can be considered rational/cognitive coping (RC-Cope), and to measure how thoughtful and planned the respondent's approach is to dealing with problems. OSI Factor 2 (Qs 18, 19, 15, 17, 30, 10 and 7) consisted of items from the self-care subscale and can be considered self-care coping (SC-Cope), and to measure relation strategies and focus on healthy living. These two coping factors are consistent with Lazarus and Folkman's (1984) two overriding 
coping functions of managing or altering the problem (problem-focused coping) and regulating the emotional response to it (emotion-focused coping).

\section{Summary data}

Summary data for the total sample are reported in Table 1. Social support was meaningfully correlated $(r \geq .32$, indicating $10 \%$ or more of shared variance; Tabachnik \& Fidell, 1996) with psychological distress and rational/cognitive coping, such that the more social support, the less psychological distress and the greater use of rational/cognitive coping. Psychological distress was also meaningfully correlated with rational/cognitive coping, such that the greater the distress the less utilisation of rational/cognitive coping strategies. Neither social undermining nor age was meaningfully correlated with any of the other variables.

Table 1

Means, Standard Deviations, Bivariate Correlations for the Total Sample, and Scale Internal Consistency Coefficients; $N=171$.

Variable

$M \quad S D \quad 1$

23

4

$5 \quad 6 \quad$ Alpha

$\begin{array}{lrrrrrrrrr}\text { 1. SS } & 21.65 & 6.89 & - & .12 & -.32 * * * & .51^{* * *} & .13 & -.01 & .93 \\ \text { 2. SU } & 15.05 & 5.16 & - & .12 & .02 & .01 & -.17^{*} & .85 \\ \text { 3. GHQ } & 14.50 & 7.91 & & & - & -.37^{* * *} & -.09 & -.21^{* *} & .91 \\ \text { 4. RC-Cope } & 42.95 & 10.42 & & & & - & .38^{* * *} & .14 & .86 \\ \text { 5. SC-Cope } & 16.05 & 6.14 & & & & - & .13 & .75 \\ \text { 6. Age } & 20.84 & 3.10 & & & & & - & -\end{array}$

Note 1: $\mathrm{SS}=6$-item Social Support scale; $\mathrm{SU}=5$-item Social Undermining scale; GHQ = 12-item General Health Questionnaire; RC-Cope $=13$-item Rational/Cognitive Coping factor; SC-Cope $=7$-item Self-Care Coping factor.

Note $2: *=p<.05 ; * *=p<.01 ; * * *=p<.001$. 


\section{Gender and Group Differences}

A MANOVA was used to test for differences across gender and groups. In this analysis, the dependent variables were social support, social undermining, psychological distress, rational/cognitive coping and self-care coping, and the independent variables were gender (male \& female) and group (unemployed \& underemployed). Significant multivariate results were obtained for the main effects of gender, $F(5,163)=2.76, p<$ .05 , and group, $F(5,163)=4.91, p<.001$. No significant interaction effect was found. At the univariate level, significant gender effects were found for social support, $F(1,167)=$ $5.90, p<.05$, and self-care coping, $F(1,167)=5.33, p<.05$. Significant group effects were found for social support, $F(1,167)=16.38, p<.001$, psychological distress, $F(1$, $167)=11.26, p<.01$, and rational $/$ cognitive coping, $F(1,167)=7.57, p<.01$. No significant interaction effects were found. For gender, males reported significantly less social support but higher levels of self-care coping than females. For group, the unemployed reported less social support, more psychological distress and less rational/cognitive coping than the underemployed. See Table 2 for summary data. 
Table 2

Means and Standard Deviations for Males and Females for Unemployed, Underemployed and Total Sample; $N=171$.

\begin{tabular}{|c|c|c|c|c|c|c|c|c|c|c|c|c|c|c|}
\hline \multirow[b]{4}{*}{ Variable } & \multicolumn{4}{|c|}{ Unemployed } & \multicolumn{3}{|c|}{ Underemployed } & \multicolumn{3}{|c|}{ Total } & \multicolumn{4}{|c|}{ Total } \\
\hline & \multirow{2}{*}{\multicolumn{2}{|c|}{$\begin{array}{l}\text { Males } \\
N=47\end{array}$}} & \multirow{2}{*}{\multicolumn{2}{|c|}{$\begin{array}{l}\text { Females } \\
N=47\end{array}$}} & \multirow{2}{*}{\multicolumn{2}{|c|}{$\begin{array}{l}\text { Males } \\
N=38\end{array}$}} & \multirow{2}{*}{$\begin{array}{l}\text { Females } \\
N=39\end{array}$} & \multirow{2}{*}{$\begin{array}{l}\text { Males } \\
N=85\end{array}$} & \multirow{2}{*}{\multicolumn{2}{|c|}{$\begin{array}{l}\text { Females } \\
N=86\end{array}$}} & \multirow{2}{*}{\multicolumn{2}{|c|}{$\begin{array}{l}\text { Unemployed } \\
\qquad N=94\end{array}$}} & \multirow{2}{*}{\multicolumn{2}{|c|}{$\begin{array}{l}\text { Underemployec } \\
\qquad N=77\end{array}$}} \\
\hline & & & & & & & & & & & & & & \\
\hline & $M$ & $S D$ & $M$ & $S D$ & $M$ & $S D$ & $S D$ & $S D$ & $M$ & $S D$ & $M$ & $S D$ & $M$ & $S D$ \\
\hline SS & 18.79 & 7.67 & 20.85 & 7.08 & 22.47 & 5.77 & $25.28 \quad 4.76$ & $20.44 \quad 7.09$ & 22.86 & 6.50 & 19.82 & 7.42 & 23.90 & 5.44 \\
\hline SU & 14.11 & 5.95 & 14.83 & 3.92 & 15.45 & 4.75 & $16.05 \quad 5.78$ & $14.71 \quad 5.46$ & 15.38 & 4.86 & 14.47 & 5.03 & 15.75 & 5.27 \\
\hline GHQ & 16.02 & 8.57 & 16.57 & 8.15 & 12.42 & 6.59 & $12.21 \quad 7.12$ & $14.41 \quad 7.91$ & 14.59 & 7.96 & 16.30 & 8.32 & 12.31 & 6.82 \\
\hline RC-Cope & 40.62 & 10.62 & 41.36 & 10.40 & 45.05 & 9.87 & 45.6210 .08 & 42.6010 .47 & 43.29 & 10.41 & 40.99 & 10.46 & 45.34 & 9.92 \\
\hline SC-Cope & 16.45 & 6.16 & 14.72 & 5.75 & 17.92 & 6.57 & $15.33 \quad 5.85$ & $17.11 \quad 6.35$ & 15.00 & 5.77 & 15.59 & 5.99 & 16.61 & 6.31 \\
\hline
\end{tabular}

Note: See Table 1 for legend. 


\section{Predicting Psychological Distress}

A multiple regression analysis was used to determine the effects of social support, social undermining and coping on psychological distress. Psychological distress (GHQ) was included as the dependent variable. The independent variables were age, gender, group (unemployed or underemployed), social support (SS), social undermining (SU), rational/cognitive coping (RC-Cope), self-care coping (SC-Cope), and an interactive term of social support and social undermining (SSxSU). The interaction term between social support and social undermining was included as previous research has suggested that an interaction between these two variables will have influence over and above their individual contributions (Vinokur, Price \& Caplan, 1996). To avoid difficulties with multicollinearity, the interaction term was calculated using a centred score approach using a deviation from the mean transformation (Tabachnik \& Fidell, 1996). Summary data for this analysis are reported in Table 3. The semi-partial regression coefficients for each predictor variable are also included in Table 3. A semi-partial regression coefficient $(s r)$ is the contribution of an individual predictor variable to the dependent variable after the other predictor variables have been statistically controlled.

The results of this analysis show that together the variables account for a significant $23 \%$ of the variance in psychological distress, $F(8,162)=6.05, p<.001$. Rational/cognitive coping was the most important predictor of psychological distress $(\beta=$ -.26) making a significant unique contribution of $s r^{2}=5.02 \%, t(162)=-2.92, p<.01$. Social support was the second most important predictor $(\beta=-.18)$ making a significant unique contribution of $2.76 \%, t(162)=-2.14, p<.05$. Lastly, group (unemployed or employed; $\beta=.15$ ) made a significant unique contribution of $2.37 \%, t(162)=1.99, p<$ .05. Predictor variables age, gender, social undermining, self-care coping and the social support/social undermining interaction term, although contributing to the overall variance, were not significant individual predictors of psychological distress. 
Table 3

Summary of Multiple Regression Analyses for variables predicting Psychological Distress; $N=171$.

Variable

$B \quad S E B$

$\beta$

$s r$

\begin{tabular}{lllll}
\hline Age & -0.35 & 0.19 & -0.14 & -0.13 \\
Gender & -0.61 & 1.14 & -0.04 & -0.04 \\
Group & 2.33 & 1.17 & $0.15^{*}$ & 0.14 \\
SS & -0.21 & 0.10 & $-0.18^{*}$ & -0.15 \\
SU & 0.21 & 0.11 & 0.13 & 0.13 \\
RC-Cope & -0.20 & 0.07 & $-0.26^{* *}$ & -0.20 \\
SC-Cope & 0.09 & 0.10 & -0.07 & 0.06 \\
SSxSU & 0.00 & 0.01 & 0.01 & 0.01 \\
& & & & \\
\hline
\end{tabular}

Note 1: Refer Table 1 for legend. SSxSU = social support by social undermining interaction term.

Note $2: *=p<.05 ; * *=p<.01$.

Note 3: $R^{2}=0.23$; Adjusted $R^{2}=0.19$.

Predicting Rational/Cognitive and Self-Care Coping

Two multiple regression analyses were conducted to determine the effects of social support, social undermining and psychological distress on coping. The two coping variables, rational/cognitive coping and self-care coping, were utilised as dependent variables. The independent variables when the dependent variable was rational/cognitive coping were age, gender, group (unemployed or underemployed), social support (SS), 
social undermining (SU), self-care coping (SC-Cope), and the interactive term of social support and social undermining ( $\mathrm{SSxSU})$. When the dependent variable was self-care coping, rational/cognitive coping was included as an independent variable. Summary data for these analyses are reported in Table 4.

Results of the analysis predicting rational/cognitive coping show that together the variables account for a significant $43 \%$ of the variance, $F(8,162)=14.95, p<.001$. Social support was the most important predictor $(\beta=.39)$ making a significant unique contribution of $s r^{2}=17.06 \%, t(162)=5.78, p<.001$. Coping self-care was the second most important predictor $(\beta=.31)$ making a significant unique contribution of $13.62 \%$, $t(162)=5.05, p<.001$. Psychological distress was the third most important predictor $(\beta=$ -.19) making a significant unique contribution of 5.02\%, $t(162)=-2.02, p<.01$. Lastly, the social support by social undermining interaction term $(\beta=-.17)$ made a significant unique contribution of $4.28 \%, t(162)=-2.69, p<.01$. Predictor variables age, gender, group and social undermining were not significant individual predictors.

When self-care coping was used as the dependent variable, the independent variables accounted for a significant $20 \%$ of the variance, $F(8,162)=5.03, p<.001$. Rational/cognitive coping was the most important predictor $(\beta=.44)$ making a significant unique contribution of $s r^{2}=13.62 \%, t(162)=5.05, p<.001$. Gender was the only other important individual predictor $(\beta=.16)$ making a significant unique contribution of $2.99 \%, t(162)=2.24, p<.05 . \quad p<.01$. Predictor variables age, group, social support, social undermining and the social support by social undermining interaction term were not significant individual predictors. 
Table 4

Summary of Multiple Regression Analyses for variables predicting Rational/Cognitive Coping and Self-Care Coping; $N=171$.

Variable

$B \quad S E B$

$\beta \quad s r$

Rational/Cognitive Coping

$\begin{array}{lcccc}\text { Age } & 0.31 & 0.22 & 0.09 & 0.11 \\ \text { Gender } & -0.29 & 1.30 & -0.01 & -0.02 \\ \text { Group } & 0.00 & 1.35 & 0.00 & 0.00 \\ \text { SS } & 0.59 & 0.10 & 0.39^{* * *} & 0.41 \\ \text { SU } & -0.00 & 0.13 & -0.00 & -0.00 \\ \text { GHQ } & -0.25 & 0.09 & -0.19^{* *} & -0.22 \\ \text { SC-Cope } & 0.53 & 0.11 & 0.31^{* * *} & 0.37 \\ \text { SSxSU } & -0.04 & 0.02 & -0.17 * * & -0.21\end{array}$

Self-Care Coping

$\begin{array}{lllll}\text { Age } & 0.08 & 0.15 & 0.04 & 0.04 \\ \text { Gender } & 1.99 & 0.89 & 0.16^{*} & 0.17 \\ \text { Group } & -0.22 & 0.94 & -0.02 & -0.02 \\ \text { SS } & -0.03 & 0.08 & -0.04 & -0.03 \\ \text { SU } & 0.02 & 0.09 & 0.02 & 0.02 \\ \text { GHQ } & 0.05 & 0.06 & 0.07 & 0.07 \\ \text { RC-Cope } & 0.26 & 0.05 & 0.44^{* * *} & 0.37 \\ \text { SSxSU } & 0.02 & 0.01 & 0.13 & 0.13\end{array}$

Note 1: Refer Table 1 for legend. SSxSU = social support by social undermining interaction term.

Note $2: *=p<.05 ; * *=p<.01 ; * * *=p<.001$.

Note 3: When predicting rational/cognitive coping, $R^{2}=0.43$; Adjusted $R^{2}=0.40$. When predicting self-care coping, $R^{2}=0.20$; Adjusted $R^{2}=0.16$. 


\section{Discussion}

\section{Group Differences}

In relation to differences between unemployed and underemployed groups, the evidence from this study is that the unemployed fared more poorly in relation to psychological distress, social support and use of rational/cognitive coping. These results are consistent with other studies that have shown differences between these two occupational groups (Creed \& Machin, 2002), and confirm that the "unemployed" should not be treated as an homogenous group. The finding is also consistent with Jahoda's (1981) latent deprivation model that predicts lower levels of the social support latent benefit for the unemployed. The unemployed perceived less social support than the underemployed group, although the two groups did not differ on levels of perceived social undermining. Having some paid employment, then, is associated with higher levels of social support but makes no difference in relation to social undermining.

When the total sample was examined, social support, but not social undermining, was associated with psychological distress. Consistent with previous studies (e.g., Jackson, 1999), social support was associated with lower levels of distress. However, no clear association emerged for social undermining. This is contrary to some previous studies that have found stronger effects for social undermining (e.g., Taylor, 1991; Vinokur \& van Ryn, 1993). Social undermining did not contribute individually to the prediction of psychological distress. Nor did it contribute to the prediction of rational/cognitive coping or self-care coping. There was a significant contribution when social undermining was combined with social support as an interaction term in the prediction of rational/cognitive coping, such that less coping was associated with lower social support and higher social undermining. The results suggest that social undermining does not influence rational/cognitive coping unless it is also associated with low levels of social support. 
Social undermining may act as a moderator between perceived social support and rational/cognitive coping, and needs to be explored in this light.

The underemployed were more likely to use strategies associated with managing problems and altering situations (rational/cognitive coping) than the unemployed. There is an internal consistency here, with underemployed people, who have negotiated job search and selection activities successfully to obtain some paid employment, having better problem-focused coping than the unemployed who have not managed this response to unemployment. This finding is consistent with Waters and Moore (2001), who found higher levels of solution-focused coping in an employed sample when compared with an unemployed sample, and suggests that unemployed people might benefit from interventions that focus on problem solving. In the present study, those with higher levels of rational/cognitive coping were also likely to have lower psychological distress and more social support. However, while rational/cognitive coping was associated with more social support it was not associated with social undermining, except where social undermining interacted with social support. This again suggests that social undermining does not play a major role in distress levels for underemployed and unemployed individuals.

No differences were identified between the two groups on levels of self-care coping, with its focus of regulating the emotional response. Waters and Moore (2001) found that their unemployed sample adopted more affective-based coping than their employed sample. Comparing these results with the present study implies that full-time paid employment may be required before a reduction in affective-based coping occurs. In the present study self-care coping was not associated with psychological distress, social support or social undermining. However, in relation to these outcomes, it should be noted that it is not possible to determine causality in relationship to group membership. Longitudinal studies would be required to determine, for example, whether high social 
support and better rational/cognitive coping is more likely to lead people to obtain employment, or whether these underemployed people receive more support and cope better because they have been able to find some work.

\section{Gender Differences}

In relation to gender differences, while there was no group by gender interaction, males perceived lower social support and used more self-care or emotion based coping. The finding concerning differences in levels of social support for males and females is consistent with other studies (e.g., Frydenberg \& Lewis, 1991). Other studies have also found that low social support is more problematic for females than males (Hammarström \& Janlert, 1997). In the present study, social support was not associated with psychological distress for males or females. One interesting finding is the combination of lower social support and higher self-care coping in males, which does imply that males in unemployment rely on other emotion based strategies than social support than unemployed females. Importantly, in the context of this study, no gender differences were found for social undermining. This is inconsistent with previous theorising (e.g., Eagly, (1983) and some studies (e.g., Conger, Lorenz, Elder, Simons, \& Ge, 1993) that have found gender differences. However, other studies using unemployed people have also failed to find gender differences (Vinokur, Price \& Caplan, 1996) on this variable. Females seeking paid employment do not differ from males on their level of social undermining.

\section{Predicting Psychological Distress and Coping}

Psychological distress in these samples was related to group, social support and rational-cognitive coping. That is, unemployed participants with some paid work, who reported receiving support from others and who used more problem focused coping, 
reported less psychological distress. The findings suggest that there is a role for problemfocused coping and social support in relation to reduced levels of distress in unemployed people, and strategies that enhance access to these supports/strategies are likely to be beneficial to this group of people. Contrary to prediction and some other research (e.g., Abbey et al., 1985), there was very little association between social undermining and distress. No direct effect was found, although there was some indirect effect of social undermining on distress via its role in prediction rational/cognitive coping. This is likely to be a small effect given the size of the social support by social undermining interaction effect on coping. This finding does not support the conceptualisation (Shinn, Lehmann \& Wong, 1984) of social undermining as an acute stressor, at least for unemployed people.

Social support, self-care coping, level of distress and the social undermining by social support interaction term, in turn, predicted rational/cognitive coping. That is, unemployed people are more likely to report using problem focused coping when they perceive receiving social support, also use emotional regulating coping, have low levels of distress and are not subject to a combination of low social support and high social undermining. Self-care coping was predicted primarily by rational/cognitive coping, and to a lesser extent, gender. This suggests that unemployed people proficient in problem-focused coping will also use emotion-focused strategies. The prediction in relation to social support predicting coping, then, was partially supported, as social support is primarily related to problem-focused coping.

The study has a number of limitations. Data collection was cross-sectional rather than longitudinal, thus making it difficult to determine causal relationships. All data collected were self-report and only from the unemployed participants. While the factor analysis gave confidence that the scales were independent, it would have been desirable to have data from other sources, such as the participants' families, and it would have been desirable to have data collected in other ways, such as independent measures of well- 
being (e.g., cortisol measures). Lastly, before the results of the study can be generalised, it needs to be replicated using other samples.

Despite these limitations, the study contributes to the literature in a number of ways. First, the findings have demonstrated differences between unemployed and underemployed people on levels of social support, psychological distress and rational/cognitive coping. Second, it has identified differences between males and females not in full-time work on levels of social support and self-care coping, and has clarified the roles of social undermining and social support in relation to psychological distress and coping. Future research needs to examine differences between the two groups on the other latent benefits of employment, and also on levels of financial strain, which have been shown to be a major determinant of psychological well-being in unemployed people and to impact on coping ability (Creed \& Macintyre, 2001; Waters \& Moore, 2001). Social undermining was not found to be an important variable associated with well-being or coping in these unemployed samples. Responses to unemployment have been shown to vary according to the prevailing unemployment rate in a community, with higher unemployment rates leading, for example, to less negative well-being effects (Jackson \& Warr, 1987). The data for the current study were collected from within an Australian State and locality with high levels of unemployment. It may be that social undermining plays a more important role for the unemployed when levels of unemployment are low, and should be tested in future studies. 


\section{References}

Abbey, A., Abramis, D., \& Caplan, R. (1985). Effects of different sources of social support and social conflict on emotional well-being. Basic and Applied Social Psychology, 6, 111-129.

Australian Bureau of Statistics. (2002). Labour force, Australia. Duration of unemployment: Recent definitional changes. Canberra: Australian Government.

Australian Bureau of Statistics. (2004) Year book, Australia. Labour article: Underemployed workers. Canberra: Australian Government.

Broomhill, H. S., \& Winefield, A. H. (1990). A comparison of the affective well-being of young and middle-aged unemployed men matched for length of unemployment. British Journal of Medical Psychology, 63, 43-52.

Caplan, R., Vinokur, A., Price, R., \& van Ryn, M. (1989). Job seeking, reemployment and mental health: A randomised field experiment in coping with job loss. Journal of Applied Psychology, 74(5), 759-769.

Cohen, S., \& Will, T. (1985). Stress, social support and the buffering hypothesis. Psychological Bulletin, 98(2), 310-357.

Creed, P. A., \& Machin, M. A. (2002). Access to the latent benefits of employment for unemployed and underemployed individuals. Psychological Reports, 90, 1208-1210.

Creed, P. A., \& Macintyre, S. R. (2001). The relative effects of deprivation of the latent and manifest benefits of employment on the well-being of unemployed people. Journal of Occupational Health Psychology, 6(4), 324-331.

Eagly, A. H. (1983). Gender and social influence: A social psychological analysis. American Psychologist, 38, 971-981.

Ensminger, M. \& Celentano, D. (1988). Unemployment and psychiatric distress: Social resources and coping. Social Science and Medicine, 27(3), 239-247. 
Frydenberg, E., \& Lewis, E. (1991). Adolescent coping: The different ways in which boys and girls cope. Journal of Adolescence, 14(2), 119-133.

Feather, N. T., \& O'Brien, G. E. (1986). A longitudinal study of the effects of employment and unemployment on school leavers. Journal of Occupational Psychology, 59, 121-144.

Feather, N. T., \& O'Brien, G. E. (1987). Looking for employment: An expectancyvalence analysis of job-seeking among young people. Journal of Occupational Psychology, 78, 251-272.

Goldberg, D. P. (1972). The Detection of Psychiatric Illness by Questionnaire. London: Oxford University Press.

Goldberg, D. P., \& Williams, P. (1988). A Users Guide to the General Health Questionnaire. Berkshire: NFER-NELSON.

Hammarström, A., \& Janlert, U. (1997). Nervous and depressive symptoms in a longitudinal study of youth unemployment - selection or exposure? Journal of Adolescence, 20, 293-305.

Hamilton, V., Hoffman, W., Broman, C., \& Rauma,, D. (1993). Unemployment, distress, and coping: A panel study of autoworkers. Journal of Personality and Social Psychology, 65, 234-247.

Henwood, F., \& Miles, I. (1987). The experience of unemployment and the sexual division of labour. In D. Fryer \& P. Ullah (Eds.). Unemployed people (pp. 94-110). Milton Keynes: Open University Press.

House, J. S. (1981). Work, stress and social support. Reading, MA: Addison-Wesley. Jackson, T. (1999). Differences in psychosocial experiences of employed, unemployed, and student samples of young adults. Journal of Psychology, 133(1), 49-60.

Jahoda, M. (1981). Work, employment and unemployment: values theories and approaches in social research. American Psychologist, 36, 184-191. 
Jackson, P. R. \& Warr, P. B. (1987). Mental health of unemployed men in different parts of England and Wales. British Medical Journal, 295, 525.

Latack, J., Kinicki, A., \& Prussia, G. (1995). An integrative process model of coping with job loss. Academy of Management Review, 20(2), 311-342.

Lazarus, R. S., \& Folkman, S. (1984). Stress, appraisal and coping. New York: Springer.

Murphy, G. C. \& Athanasou, J. (1999). The effect of unemployment on mental health. Journal of Occupational and Organizational Psychology, 72, 83-99.

Osipow, S. H., \& Spokane, A. R. (1987). Manual of the Occupational Stress Inventory: Research Version. Odessa, Florida: Psychological Assessment Resources.

Rodriguez, E., Allen, J. A., Frongillo, E., \& Chandra, P. (1999). The impact of unemployment on health and well-being. Journal of Epidemiology and Community Health, 53(6), 335-342.

Ruehlman, L. S., \& Wolchik, S. A. (1988). Personal goals and interpersonal support and hindrance as factors in psychological distress and well-being. Journal of Personality and Social Psychology, 55, 293-301.

Shinn, , M., Lehmann, S., \& Wong, N. (1984). Social interaction and social support. Journal of Social Issues, 40(4), 55-76.

Tabachnik, B. G, \& Fidell, L. S. (1996). Using Multivariate Statistics. New York: HarperCollins College Publishers.

Taylor, S. E. (1991). Asymmetrical effects of positive and negative events: The mobilization-minimization hypothesis. Psychological Bulletin, 110, 67-85.

Thoits, P. A. (1986). Social support as coping assistance. Journal of Consulting and Clinical Psychology, 54, 416-423.

Vaux, A. (1988). Social support: Theory, research and intervention. New York: Praeger. 
Vinokur, A. D., Price, R. H., \& Caplan, R. D. (1996). Hard times and hurtful partners: How financial strain affects depression and relationship satisfaction of unemployed persons and their spouses. Journal of Personality and Social Psychology, 65, 350-359.

Vinokur, A. D., Schul, Y., \& Caplan, R. D. (1987). Determinants of perceived social support: Interpersonal transactions, personal outlook and transient affective states. Journal of Personality and Social Psychology, 53, 1137-1145.

Vinokur, A. D., \& van Ryn, M. (1993). Social support and undermining in close relationships: Their independent effects on the mental health of unemployed persons. Journal of Personality and Social Psychology, 65(2), 350-359.

Vinokur, A. D., \& Vinokur-Kaplan, D. (1990). “In sickness and in health:” Patterns of social support and undermining in older married couples. Journal of Aging and Health, 2, 215-241.

Wanberg, C. R. Watt, J. D. \& Rumsey, D. J. (1996). Individuals without jobs: An empirical study of job-seeking behaviour and reemployment. Journal of Applied Psychology, 81. 76-87.

Waters, L. E., \& Moore, K. A. (2001). Coping with economic deprivation during unemployment. Journal of Economic Psychology, 22(4), 461-482.

Warr, P. B. (1987). Work, unemployment and mental health. Oxford: Oxford University Press.

Warr, P. B., \& Jackson, P. (1987). Adapting to the unemployed role: A longitudinal investigation. Social Science and Medicine, 25(11), 1219-1224.

Warr, P. B., Jackson, P., \& Banks, M. (1988). Unemployment and mental health. Journal of Social Issues, 44(4), 47-68.

Weiss, R. S. (1973). Loneliness: The experience of social and emotional isolation. England: The MIT Press. 
Winefield, A. H. (1995). Unemployment: Its psychological costs. In C. L. Cooper \& I. T. Robertson (Eds.). International Review of Industrial and Organizational Psychology. Chichester: Wiley. 